seen again on Sept. 10th when the testicle was at the bottom of the scrotum.

The interest of the case lies in the extreme rarity of the condition. Jacobson ${ }^{1}$ quotes two cases under the care of Dr. W. Popow, and Mr. Bilton Pollard ${ }^{2}$ had a case under his care. In the literature at my disposal I have been unable to find records of any other case.

Calcutta.

\section{A CASE OF OARDIAO HYPERTROPHY WITH VALVULAR CALCIFICATION.}

By Damodar Babaji Mandhle, L.R.C.P., L.R.C.S Edin., L.F.P.S. GI.ASG.

THIs case seems to be worthy of being recorded on account of the unusual weight and size of the heart.

The patient was a man, aged 20 years, who was admitted into the Liverpool Poor-law infirmary on Sept. 23rd, 1905 in a collapsed state and suffering from vomiting and hæmoptysis. The physical signs referable to the heart were apical thrill, epigastric pulsation, evidence of failing compensation, double mitral and aortic murmurs, and cardiac dyspncea. There was no œdema of any part of the body except at the bases of the lungs. The liver and spleen were slightly enlarged; the urine was normal. The previous history was to the effect that he had an attack of rheumatism a few years ago. The gastric symptoms passed away under treatment but the patient gradually became worse, his dyspnoez and nausea could not be controlled, and he died on Oct. 15th. At the necropsy his heart was found to be greatly hypertrophied with dilatation. It weighed 35 ounces when full of clot and $30 \frac{1}{2}$ ounces without the clot. 'The muscular fibres were hypertrophied; the mitral and aortic valves were a mass of calcareous plaques, and the other organs showed signs of extreme congestion and enlargement. Liverpool.

\section{AN OCCURRENCE OF THE THIRD EYELID IN A HUMAN SUBJECT.}

By Wiluiam Robertson, M.D. GLasG.

A BRIE reference to what may be called a very perfect example of this rare vestigium will, no doubt, be of interest to some readers of THE LANCET. I met with it in an adult male Indian of Dravidian stock who displayed no other physical defect. This supernumerary eyelid was situated under the right upper eyelid and protruded when the eye was in natural function two millimetres beyond the margin of the natural lid. This exposed part which led to the discovery was darker than the rest of the structure, the latter approximating to the colour of the conjunctiva. It was normally sensitive and cartilaginous to the touch. Of the thickness of a sixpence it evenly and completely followed the contour and movement of the upper lid, lying closely over the globe without fold or corrugation on either surface and with a clean-cut margin at its periphery. From a perusal of the above it will be recognised that the condition was an example of the plica semilunaris or membrana nictitans of birds and reptiles. It will be remembered that the conjunctiva is developed from the surface epiblast and that the membrana nictitans divides the conjunctival sac into two portions in birds and reptiles.

I think it will be admitted that this survival is a striking proof, perhaps unique of its kind, of the evolutionary element in nature. Environment, I suppose, would be cited in this connexion.

Durban, Natal.

Jacobson: Diseases of the Male Organs of Genera'ion. B. Pollard: Medical Chronicle, December, 1895

Association of Medical Diplomates of ScotLAND.-The winter session of this association will be opened by a conversazione to be held at 11, Chandos-street, Cavendish-square, London, W., on Tuesday next, Nov. 7th, from 9 to $12 \mathrm{P}$ II. There will be light refreshments, music, and other entertainments, and ladies are invited. Each member is entitled to one licliet for a guest, but may obtain extra tickets at $2 s .6 d$. each by conmunicating with Dr. David Walhh, the honorary secretary, at $18 \mathrm{~A}$, Hanover-street, London, W.

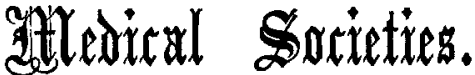

\section{CLINICAL SOCIETY OF LONDON.}

\section{Exhibition of Cases and Specimens.}

A CLINICAL evening of this society was held on Oct. 27th, Mr. H. H. Clutton, the President, being in the chair.

Dr. G. E. O. WrLLIAMs (introduced by Dr. H. BATTY SHAw) showed a case of Intrathoracic Dermoid Cyst, which is published in full in this issue of THE LANCET (p. 1325).Mr. W. G. SPENCER described a specimen that was in the museum of Westminster Hospital. These tumours usually grew in the neighbourhood of the thymus which was a region. of physiological rests.- Mr. RICKMAN J. GODLEE mentioned a case on which he operated in 1889 . These tumours usually communicated with a bronchus and so, if drained, never healed up but remained moist. In the present instance he was of opinion that it was too extensive for removal but he advocated making a large incision with free drainage.Dr. BATTY SHAW mentioned seven cases that had been operated on. Two had been completely cured, one by removal of the tumour and one by drainage.

Dr. STClaIr Thomson showed three cases of Submucous Excision of Deviations and Spurs in the Nasal Septum. The operation to which the patients had submitted was as follows. An incision was made through the mucous membrane of the septum, inside the vestibule of the nose. Through this incision the muco-perichondrium was separated all over the convexity. The cartilage was then cut through a little in front of the original incision but without incising the mucoperichondrium of the opposite side, and the mucous membrane and perichondrium were separated from the concave side of the deformity. The deviation, thus freed on both sides from its mucous covering, was cut out, any bony spur was clipped or chiselled away, and the two mucous membranes were allowed to fall together. The original incision was then closed by two or three stitches. Healing was rapid, there was no formation of crusts, and the nose was left with an intact mucosa. The result was always satisfactory and permanent.

Mr. EDRED M. CORNER showed a series of Cases of Recovery without Spinal Symptoms after Severe Injury to the Neck. 1. A case of Fracture of the Pedicles of the Axis. This case with skiagram had been shown at a meeting of the society on Jan. 22nd, 1904. The accident was the result of the patient rolling out of his chair whilst asleep. Since being shown he had recovered full power of movement of his neck and began to drive his cab again 12 weeks after the accident. 2. A case of Fracture of the Body and Pedicles of the Fifth Cervical Vertebra. This case with skiagram had also been exhibited on Jan. 22nd, 1904. The accident occurred during a gymnastic display on the stage. Since being shown he had resumed his occupation as a professional acrobat. 3. A case of Rotatory Dislocation of the Atlas. This case with skiagram had also been previously shown. The patient's head was still turned to one side but he had to some extent recovered the power of movement. 4. A case of Lateral Fracture of the Axis with Unilateral Rotatory Dislocation of the Atlas. The specimen from this case showed at least one fracture of the atlas, and, by the signs of healing, that the patient had lived after the injury. Moreover, the displaced fragments made new articular facets for themselves, so that there was no paralysis in this situation and therefore presumably none elsewhere. 5. A case of Subluxation of the Atlanto-axial Joint. This case was that of a boy, 13 years of age, who hurt his neck while diving. His head was rotated to one side and his neck was stiff, painful, and immoveable. He was seen a month after the accident and had never had any paralytic symptoms. Reduction was easily accomplished under an anæsthetic. The boy wore a poroplastic collar for a week or so; since then he had completely recovered all his movements, so that it would be impossible to know that he had received a severe injury to his cervical spine. 6. A case of Lateral Fracture of the Axis. A man, 50 years of age, was thrown from his horse on to the top of his head. There had been no paralytic symptoms. The injury took place about seven years ago. He had now recovered full movement and experienced no trouble from his injury. The skiagram showed ankylosis and deformity of the axis. -Mr. C. H. FAGGE considered that the specimen from. 